\title{
Lactobacillus fermentum and Lactobacillus plantarum increased gut microbiota diversity and functionality, and mitigated Enterobacteriaceae, in a mouse model
}

\author{
Linninge, C.; Xu, J.; Bahl, Martin lain; Ahrné, S.; Molin, G
}

Published in:

Beneficial Microbes

Link to article, DOI:

10.3920/BM2018.0074

Publication date:

2019

Document Version

Version created as part of publication process; publisher's layout; not normally made publicly available

Link back to DTU Orbit

Citation (APA):

Linninge, C., Xu, J., Bahl, M. I., Ahrné, S., \& Molin, G. (2019). Lactobacillus fermentum and Lactobacillus plantarum increased gut microbiota diversity and functionality, and mitigated Enterobacteriaceae, in a mouse model. Beneficial Microbes, 10(4), 413-424. https://doi.org/10.3920/BM2018.0074

\section{General rights}

Copyright and moral rights for the publications made accessible in the public portal are retained by the authors and/or other copyright owners and it is a condition of accessing publications that users recognise and abide by the legal requirements associated with these rights.

- Users may download and print one copy of any publication from the public portal for the purpose of private study or research.

- You may not further distribute the material or use it for any profit-making activity or commercial gain

- You may freely distribute the URL identifying the publication in the public portal 


\title{
Lactobacillus fermentum and Lactobacillus plantarum increased gut microbiota diversity and functionality, and mitigated Enterobacteriaceae, in a mouse model
}

\author{
C. Linninge ${ }^{1,4}$, J. Xu' ${ }^{2}$, M.I. Bahl ${ }^{3}$, S. Ahrné ${ }^{1}$ and G. Molin ${ }^{1 *}$ \\ ${ }^{1}$ Department of Food Technology, Engineering and Nutrition, Lund University, 22100 Lund, Sweden; ${ }^{2}$ Department of \\ Clinical and Experimental Medicine, Linköping University, 58225 Linköping, Sweden; ${ }^{3}$ National Food Institute, Technical \\ University of Denmark, Kgs. Lyngby, Denmark; ${ }^{4}$ BioGaia AB, Mobilvägen 10, 22362 Lund, Sweden; goran.molin@food.lth.se
}

Received: 4 June 2018 / Accepted: 10 December 2018

(c) 2019 Wageningen Academic Publishers

OPEN ACCESS C(1) RESEARCH ARTICLE

\begin{abstract}
Probiotics should bring 'balance' to the intestinal microbiota by stimulating beneficial bacteria, whilst mitigating adverse ones. Balance can also be interpreted as high alpha-diversity. Contrary, Escherichia coli is often regarded as an adverse component of the resident intestinal microbiota. The aim of the present study was to implement a mouse model for in vivo screening of Lactobacillus-strains for ability to increase gut-microbiota diversity and to mitigate $E$. coli. Mice were divided into six groups, two dietary control-groups and four groups administered strains of Lactobacillus fermentum and/or Lactobacillus plantarum. All animals were pre-treated with antibiotics, and E. coli in order to equalise the microbiota from the start. After 7 weeks of Lactobacillus administration, the animals were sacrificed: DNA was extracted from caecum tissue, and the microbiota composition was analysed with terminal restriction fragment length polymorphism (T-RFLP) and 16S rRNA gene sequencing. The diversity of the caecal microbiota decreased when the dietary carbohydrate source was limited to corn starch. Conversely, the diversity was restored by Lactobacillus-supplements. The tested combinations of two Lactobacillus strains exerted different influences, not only on the taxonomic level, but also on the inferred microbiome functions. The mixture of L. fermentum GOS47 and L. fermentum GOS1 showed potential for anti-inflammatory activity and short chain fatty acid production. On the other hand, co-administration of L. fermentum GOS57 and L. plantarum GOS42 significantly decreased the viable count of Enterobacteriaceae. These results warrant further investigation of the tested strains as candidates for probiotics. Furthermore, the findings demonstrated that the current experimental animal model is suitable for in vivo studies of the effect of bacterial supplements on the gut-microbiota.
\end{abstract}

Keywords: probiotics, screening, microbiota, microbiome-functions

\section{Introduction}

A traditional view on probiotics is that the administrated, live microorganism shall bring 'balance' to the intestinal microbiota and mitigate adverse bacteria (Fuller, 1989; Parker, 1974). Balance can also be interpreted in terms of high alpha-diversity. In contrast, examples of adverse components of the intestinal microbiota, that can cause overgrowth and, hence, severely decreased diversity are genera of the family Enterobacteriaceae, and in mammalians especially the species Escherichia coli. Pro-inflammatory lipopolysaccharides (LPS) are associated to the cell surface of E. coli (Poxton and Edmond, 1995). Furthermore, specific strains of $E$. coli can also be invasive, enterotoxin producing, and carrier of multiple antibiotic resistance genes. One example of an adverse effect of commonplace $E$. coli, is that early colonisation in infants increases the risk for atopic eczema later in life (Penders et al., 2007), and the same effect has low diversity, early in life (Abrahamsson et al., 2012; Ismail et al., 2012; Wang et al., 2008). It has also been observed that Enterobacteriaceae are abundant in the colonic mucosa of patients suffering from diverticular disease (Linninge et al., 2018). A clinically problem of considerable magnitude involving $E$. coli is urinary tract infections (UTIs) where it has been seen that uropathogenic E. coli often dominates the faecal microbiota of the 
patients (Yamamoto et al., 1997). Uropathogenic E. coli has a capacity to migrate from the intestinal tract to the urinary tract, and E. coli is the infecting agent in about $80 \%$ of all UTIs, (Hooton and Stamm, 1997; Svanborg and Godaly, 1997). Uropathogenic strains of E. coli with multiple antibiotic resistance is of special public concern, because such infection can't be efficiently treated with antibiotics. Mouse-models are frequently used in preclinical investigations. For example, colitis in mouse strongly alter the colonic microbiota (Håkansson et al., 2015) and increases the abundance of Enterobacteriaceae (Constante et al., 2017). Another mouse model was used for in vivo verification of a potential probiotic strain selected by in vitro tests (Silva et al., 2016), but the promising achievements failed to deliver in vivo.

The aim of the present study was to implement a mouse model for in vivo screening of different Lactobacillusstrains with probiotic potential, and search for strains able to increase microbiota diversity and to reduce the relative abundance of Enterobacteriaceae in vivo. The applied mouse model has previously been developed for this purpose (Linninge et al., 2015). The gut microbiota between different animals is in the model initially equalised by a short antibiotic pre-treatment followed by $E$. coli administration. Three novel strains of Lactobacillus fermentum and one of Lactobacillus plantarum were tested in combinations, in order to minimise the number of animals. The teststrains were compared with the scientifically established, and commercially available probiotic strain L. plantarum 299v (Molin, 2008). The caecal microbiota composition and diversity of the mice was investigated by $16 \mathrm{~S}$ rRNA gene sequencing and terminal restriction fragment length polymorphism (T-RFLP).

\section{Material and methods}

\section{Experimental set-up}

Male C57BL/6NCrl mice, 8 weeks old with body weight 18.9 to $22.5 \mathrm{~g}$, were purchased from Charles River laboratories (Sulzfeld, Germany), and randomly divided into six groups (eight animals/group; one cage/group). The animals were maintained in a temperature-controlled environment on a 12-h light/dark cycle. All experiments followed the national guidelines for the care and use of animals, and the study was approved by the Malmö/Lund regional ethics committee for laboratory animals (ethical permission, M209-11). All animals were pre-treated according to Linninge et al. (2015) in order to equalise the microbiota before the beginning of the test-series. Briefly, an antibiotic cocktail of ampicillin, metronidazole and clindamycin was given daily for three days in the drinking water (Linninge et al., 2015). The antibiotics were consumed at clinical relevant doses. Two non-pathogenic strains of $E$. coli were then given in the drinking water, for two days (Linninge et al., 2015). Water consumption was determined daily, and an average dose of $10^{8} \mathrm{cfu}$ of each $E$. coli strain was consumed by each mouse.

\section{Diet and bacterial supplementation}

The widely used and well-known, purified rodent diet AIN-76A was given to one group, while five groups were given a custom designed, purified open source, corn starch diet (CS-ctrl diet); with the intention to stimulate Enterobacteriaceae in the gut. The general composition of the CS-diet is based on AIN-76A. Both diets had an energy composition of $20.8 \mathrm{E} \%$ protein, $67.7 \mathrm{E} \%$ carbohydrates and $11.5 \mathrm{E} \%$ fat, and corn oil is the source of fat in both diets. The carbohydrates are provided by corn starch and sucrose in AIN-76A, while the sucrose was replaced by additional corn starch in the CS-diet; the total amount of carbohydrates was the same in both diets. Both diets were produced by Research Diets (New Brunswick, NJ, USA). The CS-ctrl diet was previously composed by Linninge et al. (2015) and was called 'research diet' (RD). Feed was administered ad libitum. After the five days pre-treatment, animals were given different Lactobacillus-strains in the drinking water for seven weeks according to Table 1.

The novel strains of L. fermentum GOS47, L. fermentum GOS1, L. fermentum GOS57 and L. plantarum GOS42 (= DSM 32131) have all been isolated from human saliva of healthy young adults. L. plantarum $299 \mathrm{v}$ was originally isolated from healthy human intestinal mucosa (Molin et al., 1993). The Lactobacillus-strains were supplemented in the drinking water. Drinking water with bacterial supplement was changed daily; each animal consumed $5 \times 10^{7}$ to $1 \times 10^{8}$ cfu of Lactobacillus per day.

\section{Animal sacrifice and sampling}

After seven weeks with bacterial supplementation in the drinking water, animals were sacrificed by $\mathrm{CO}_{2}$ inhalation. The abdomen and chest were opened and spleen, liver,

Table 1. Dietary regime and bacterial supplements.

\begin{tabular}{lll} 
Group & Diet $^{1}$ & Bacterial strains \\
AIN-76A & AIN-76A & - \\
CS-ctrl & CS & - \\
$299 v$ & CS & Lactobacillus plantarum $299 \mathrm{v}$ \\
LF & CS & Lactobacillus fermentum GOS47 + L. fermentum \\
& & GOS1 \\
LP & CS & L. fermentum GOS57, L. plantarum GOS42 \\
LFP & CS & GOS47 + GOS1 + GOS57 + GOS42 \\
\hline
\end{tabular}

${ }^{1} \mathrm{AIN}-76 \mathrm{~A}$ is a traditional, purified rodent diet; CS is a custom designed, purified open source diet where the sucrose in AIN-76A had been replaced by corn starch. 
small intestine (SI), caecum and epididymal fat pads were carefully dissected and weighed. Caecum tissue (rinsed in sterile PBS) and caecum content (stored in glycerol buffer; Karlsson et al., 2011b) were immediately frozen on dry ice, and then stored at $-80^{\circ} \mathrm{C}$ until analysis.

\section{DNA extraction}

DNA from caecum tissue was extracted according to Sand et al. (2015) with the modification that $100 \mu l$ Phosphate Buffered Saline (PBS, Oxoid, Basingstoke, UK) was added to $100 \mu \mathrm{l}$ supernatant before extraction in the EZ1 Advanced $\mathrm{XL}$ and eluted in $200 \mu \mathrm{l}$.

\section{Terminal restriction fragment length polymorphism}

Endpoint PCR was performed in a reaction of $25 \mu \mathrm{l}$, including 1-3 $\mu$ template, for 25 cycles according to Sand et al. (2015). Terminal restriction fragment length polymorphism (T-RFLP) analysis including digestion with the restriction endonuclease MspI was performed as previously described (Sand et al., 2015). Thresholds for internal standard and terminal restriction fragments (T-RFs) were set to 20 and 40 fluorescence units, respectively.

\section{Next generation sequencing}

Next generation sequencing of the gut microbiota was performed using ion torrent sequencing with the Ion Torrent PGM platform (Life Technologies, Carlsbad, CA, USA) at the Technical University of Denmark (DTU) core facility (Lyngby, Denmark), in accordance with Sand et al. (2015). The primers were the same as used by Tulstrup et al. (2015), which were targeting V3 region of the $16 \mathrm{~S}$ rRNA gene. The PCR reactions were conducted with 4 $\mu \mathrm{l}$ HF-buffer, $0.4 \mu \mathrm{l}$ dNTP (10 mM of each base), $1 \mu \mathrm{M}$ forward primer, $1 \mu \mathrm{M}$ reverse primer, $5 \mathrm{ng}$ template DNA, and $0.2 \mu \mathrm{l}$ Phusion High-Fidelity DNA polymerase (F-530S, Thermo Scientific, Waltham, MA, USA) in a total reaction volume of $20 \mu \mathrm{l}$.

Sequences were demultiplexed and primers were removed using CLC bio genomic workbench (Qiagen, Hilden, Germany). Further quality trimming was performed using default settings (quality score $=0.05$, trim ambiguous nucleotides $=2$ ) only reads with a final length between 110$180 \mathrm{bp}$ were kept for downstream analysis. The number of good quality reads used for taxonomical assignment ranged from 19,225 to 98,494 per sample. The filtered sequences were then processed with an open source bioinformatics tool QIIME2 (https://qiime2.org/) (Caporaso et al., 2010). The sequences were further denoised with Qiime 2 plugin dada2 (Callahan et al., 2016). The resulting amplicon sequence variants (ASVs) were used for diversity analyses (alpha and beta) and taxonomic classification. The Naïve Bayes classifier was trained on V3 region sequences of
Greengenes 13_8 release (99\% operational taxonomic units (OTUs)) (DeSantis et al., 2006) using QIIME2 plugin feature-classifier. Subsequent multivariate data analyses were performed at Calypso online web-server (Zakrzewski, 2017). Besides the taxonomic profiling, inferred metagenomes were predicted using PICRUSt (version 1.1.2) (Langille et al., 2013). The predicted metagenome was further analysed with HUMAnN 0.99 (Abubucker et al., 2012) and statistical analyses were performed using STAMP v2.1.3 (Parks et al., 2014).

\section{Quantitative PCR}

Bacterial abundance of: total bacteria, the Clostridium leptum-group, the Bacteroides fragilis-group and the family Enterobacteriaceae were estimated in caecal tissue using separate quantitative PCR assays as previously described (Karlsson et al., 2011a; Linninge et al., 2015). Detection limit was $10^{4}$ copies of $16 \mathrm{~S}$ rRNA genes/reaction for total bacteria, $10^{2}$ copies of $16 \mathrm{~S}$ rRNA genes/reaction for both the C. leptum-group and Enterobacteriaceae. The B. fragilisgroup had a detection limit of $10^{3}$ copies/reaction. Samples below detection limit were set to the lowest detection limit for each specific assay. For standard curves, 10-fold dilution series of the target DNA were made in EB-buffer (Qiagen). Bacterial numbers were expressed as $\log 1016 \mathrm{~S}$ rRNA genes/g caecum tissue.

\section{Viable count of Enterobacteriaceae and lactobacilli}

Caecum content was thawed and homogenised in glycerol buffer (Karlsson et al., 2011b) containing freezing medium, diluted and plated on Rogosa agar (Oxoid Ltd.) and incubated anaerobically at $37^{\circ} \mathrm{C}$ for $72 \mathrm{~h}$ for lactobacilli count, and plated on violet red bile dextrose agar (VRBD), and incubated aerobically at $37^{\circ} \mathrm{C}$ for $24 \mathrm{~h}$ for Enterobacteriaceae count (Merck, Darmstadt, Germany).

\section{Calculations}

Bacterial diversity based on T-RFLP was estimated by calculation of richness (number of T-RFs) and Shannon and Simpson diversity indices as previously described (Sand et al., 2015). Statistical analyses were performed in GraphPad Prism 7 (La Jolla, CA, USA) using Kruskal-Wallis test and Dunn's multiple comparisons test to reveal differences compared to group CS-ctrl. $P<0.05$ was considered statistically significant. Statistical analyses on the $16 \mathrm{~S}$ amplicon data and the inferred metagenome data obtained by PICRUSt (Langgille et al., 2013) were performed at Calypso online web-server (Zakrzewski, 2017). 


\section{Results}

\section{Animal status}

The pre-treatment with antibiotics and E. coli were well tolerated by all animals. No adverse effects were observed, and no signs of disease occurred during the experimental period. In group LFP, one animal was injured, probably by other animals; the injured animal was removed from the cage and excluded from the study. No difference in feed consumption was observed between the groups. Animals of the control group with the CS-diet, and without any Lactobacillus supplementation (CS-ctrl), had a significantly $(P<0.05)$ lighter small intestine than animals of the AIN-76 diet. No other statistically significant differences in animal constitution were seen between the different test groups (Table 2).

\section{Microbiota}

The sequencing failed in two samples, one from group AIN-76A and one from CS-ctrl, and therefore these mice were removed from the sequencing analysis. Lactobacillus supplementation increased the diversity of the microbiota and changed its structure: Firmicutes and Bacteroidetes were the most dominating phyla followed by Actinobacteria in all groups, while Tenericutes were more abundant in the two dietary control groups without Lactobacillus supplementation (AIN-76 and CS-ctrl, respectively; Figure 1). Abundant taxa differed between the groups: At the hierarchical levels of family and of genus distinctive clusters were formed (Figure 2). Different bacterial genera were found statistically enriched with large effect size, between the animal groups (Figure 3). For example, Bifidobacterium was favoured in the group 299v, and Lactobacillus abundance was highest in the LP group (Figure 3).

Table 2. Median values, and interquartile ranges, of body and organ weights of mice in different test groups. ${ }^{1}$

\begin{tabular}{lllllll} 
Weight (g) & \multicolumn{2}{l}{ Animal groups $^{2}$} & & & & \\
\cline { 2 - 7 } & \multicolumn{1}{l}{ AIN-76A } & CS-ctrl & $299 \mathbf{v}$ & LF & LP & LFP \\
nody & $29(28.7-31.3)$ & $27.1(26.6-27.8)$ & $28.1(25.6-28.7)$ & $28.1(27.2-29.8)$ & $27.6(26.527 .9)$ & $26.2(25.6-28.7)$ \\
Spleen & $0.070(0.067-0.087)$ & $0.064(0.063-0.073)$ & $0.064(0.062-0.068)$ & $0.066(0.064-0.072)$ & $0.073(0.064-0.084)$ & $0.063(0.061-0.072)$ \\
Liver & $1.4(1.31-1.51)$ & $1.27(1.20-1.38)$ & $1.19(1.04-1.30)$ & $1.21(1.17-1.28)$ & $1.19(1.01-1.26)$ & $1.12(1.10-1.19)$ \\
Epidymal fat pad & $0.757(0.548-0.936)$ & $0.628(0.528-0.790)$ & $0.607(0.494-0.754)$ & $0.597(0.435-0.772)$ & $0.464(0.385-0.664)$ & $0.463(0.41-0.536)$ \\
Small intestine & $0.035^{*}(0.032-0.042)$ & $0.025(0.019-0.028)$ & $0.024(0.021-0.026)$ & $0.030(0.024-0.033)$ & $0.030(0.024-0.033)$ & $0.023(0.021-0.025)$ \\
Caecum & $0.239(0.218-0.264)$ & $0.264(0.235-0.271)$ & $0.266(0.231-0.285)$ & $0.263(0.233-0.286)$ & $0.275(0.221-0.328)$ & $0.275(0.218-0.306)$ \\
\hline
\end{tabular}

${ }^{1}$ An asterisk denotes statistically significant difference compared to CS-ctrl, $P<0.05$.

${ }^{2}$ Animal diet groups are explained in Table 1.

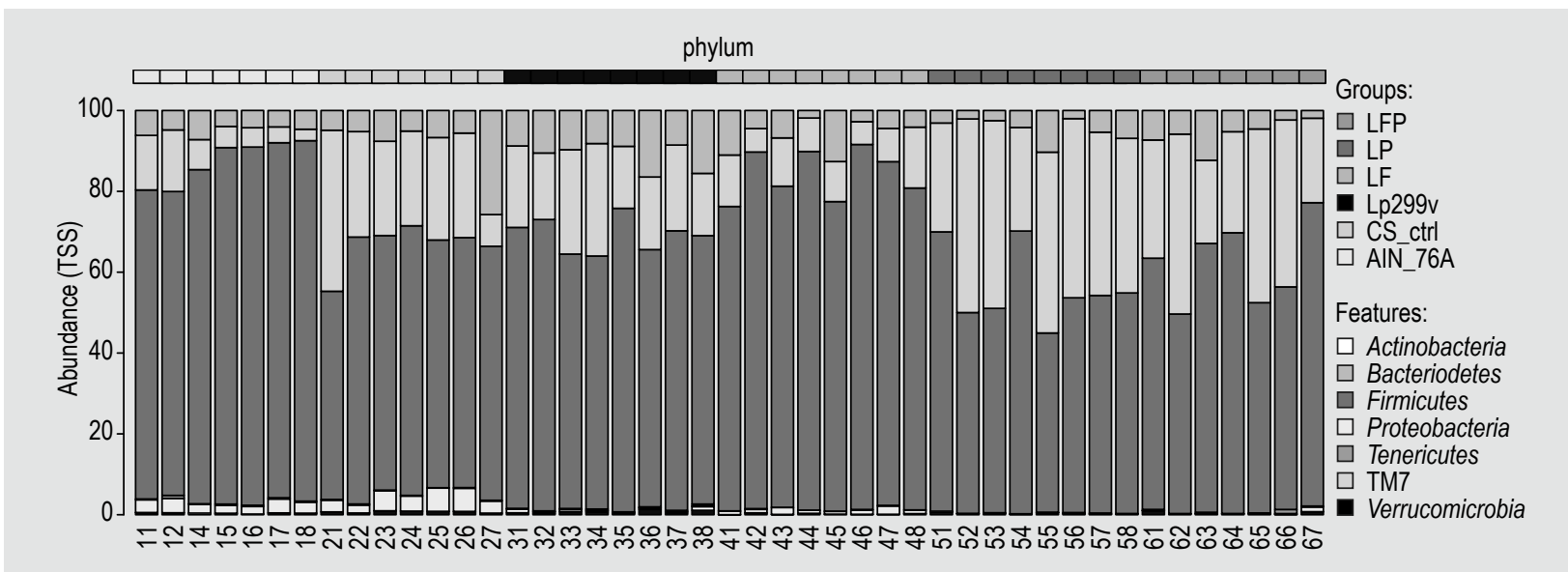

Figure 1. Bar plot of relative abundance of the mice caecal microbiota at phylum level. Horizontal greyscale code bars at the top indicate the different treatment groups. One bar corresponds to one mouse and numerical numbers are the randomisation identities of the animals. 

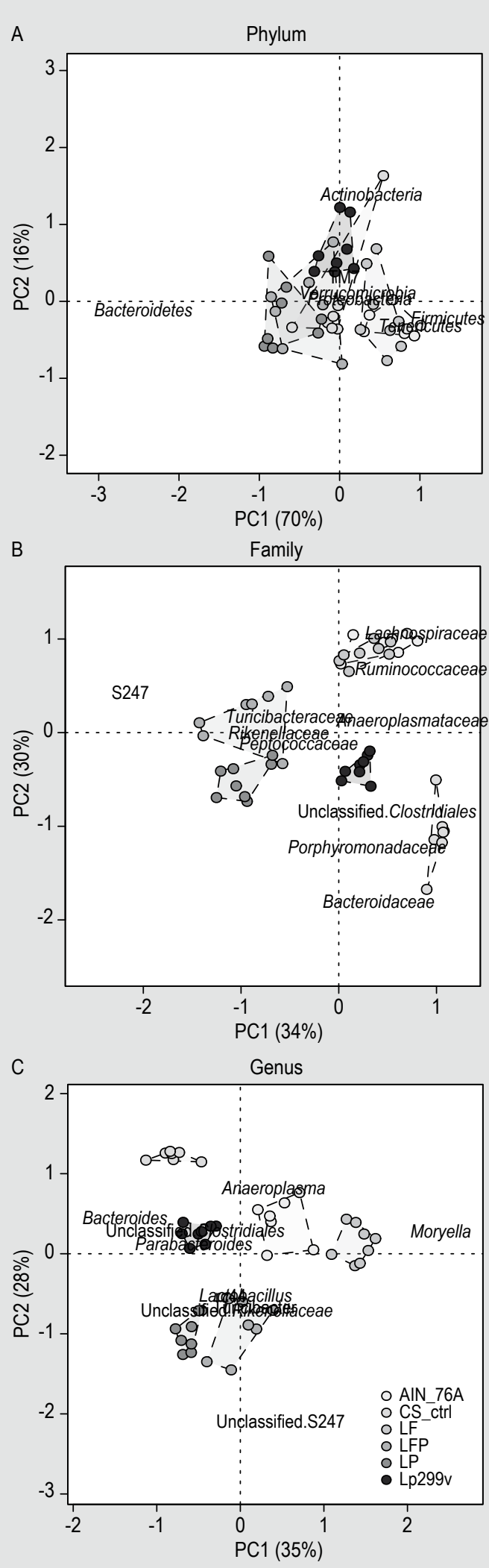

Figure 2. Principal component analysis (PCA) of the relative abundance of mice caecal microbiota at different hierarchical levels. One dot represent one animal and different diet groups are shown with different greyscales. The location of the taxa shows how those bacteria drive the separation of the groups.
The dietary change in carbohydrate source, where sucrose was replaced by corn starch, decreased the microbiota diversity in the CS-ctrl group, while Lactobacillus supplementation restored the diversity (Table 3 ). There was also a significant difference in the beta diversity between the six treatment groups $(P<0.001$, PERMANOVA on Bray Curtis distances, Figure 4).

Lactobacillus supplementation increased the lactobacilli population and suppressed Enterobacteriaceae, but the total amount of bacterial 16S rRNA genes in caecum tissue, and the number of genes in the C. leptum group did not differ depending on dietary regime or bacterial supplement (Table 3). 16S rRNA genes of Bacteroides fragilis were not detectable in any of the groups. No 16S rRNA genes of Enterobacteriaceae were found in groups AIN-76A, 299v, LF, LP and LFP. 16S rRNA genes of Enterobacteriaceae above the detection limit of PCR, could only be quantified in the CS-ctrl group. The amount corresponded to log $6.8116 \mathrm{~S}$ rRNA gene copies/gram caecum tissue, with an interquartile range of 6.24-7.3. In contrast, Enterobacteriaceae enumerated by viable count were found in all groups, indicating a certain effect of the pre-treatment procedure. Viable count had a lower detection level than PCR in the present settings. The supplementation of L. fermentum GOS57 + L. plantarum GOS42 in group LP resulted in a significant decrease in the number of Enterobacteriaceae, compared to CS-ctrl group (Table 3).

Supplementation of Lactobacillus in groups 299v, LF and LP significantly increased the viable count of lactobacilli in caecum content (Table 3). Lactobacilli of non-probiotic origin were found in the AIN-76A group, while the CS-ctrl group lacked detectable lactobacilli, which also was one purpose of the pre-treatment procedure of the animals.

\section{Microbiome}

Inferred microbiome functions differed between groups: Inferred metagenomic profiles were different between the two dietary control groups, but also between groups supplemented with different Lactobacillus strains (Figure 5). Ten KEGG pathways and six KEGG modules were significantly different between AIN-76 and CS-ctrl (Figure 6). After observing the considerable differences between the two control groups, the Lactobacillus supplemented groups were compared with CS-ctrl. Abundance of 15 KEGG pathways and 16 KEGG modules were significantly different with large effect size (Table 4). For instance, pathways involved in the short chain fatty acids (SCFAs) production (Ko00620, ko00640) were enriched in the LF and 299v groups compared to CS-ctrl. On the other hand, multiple sugar transport system (M00207) was most abundant in the CS-ctrl group. 


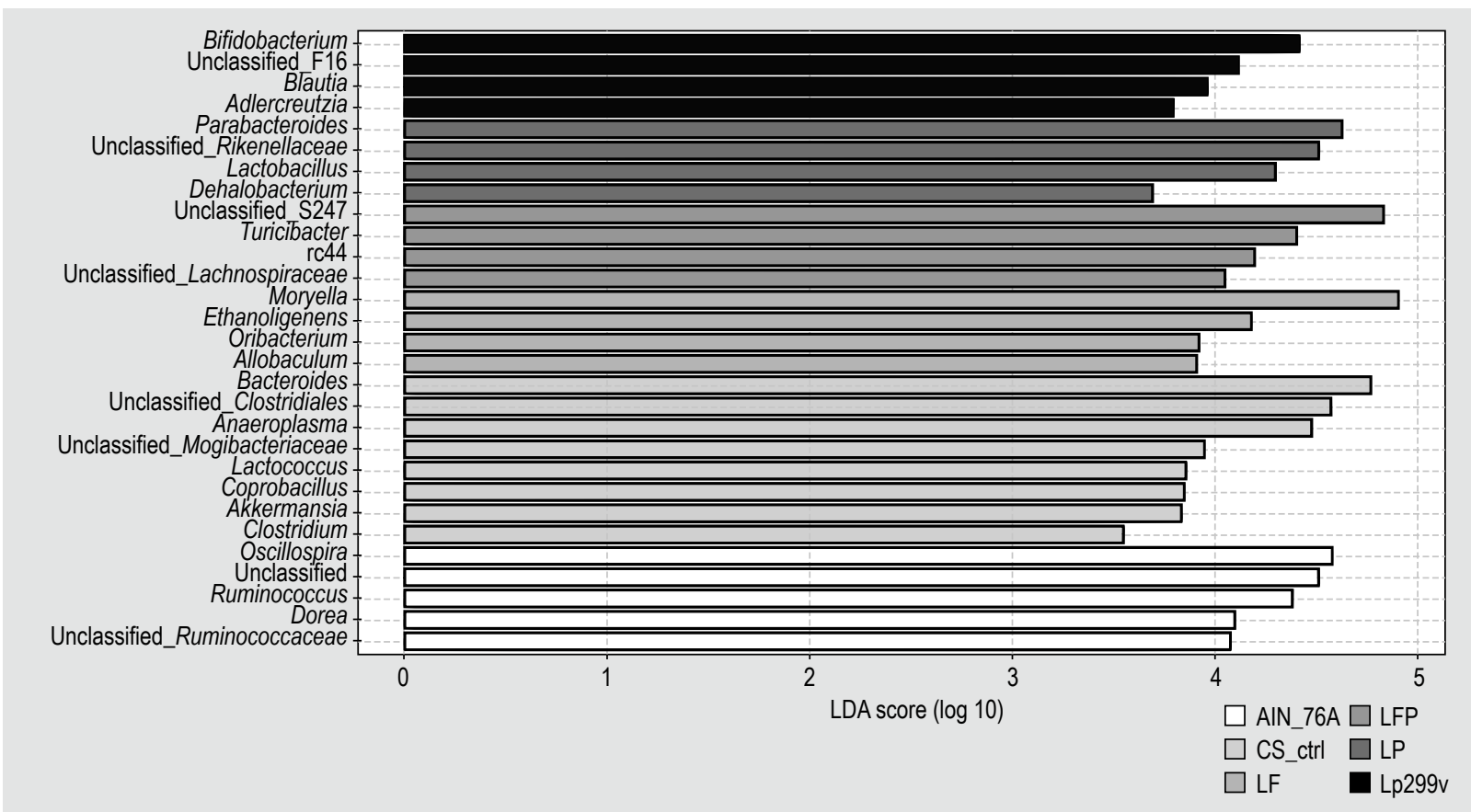

Figure 3. Significantly enriched genera among the tested six groups revealed by linear discriminant analysis coupled with effect size (LEFSe). Statistical significance was set to $P<0.05$ and LDA $>3.0$.

Table 3. Diversity based on next generation sequencing (NGS) and terminal restriction fragment length polymorphism (T-RFLP), quantification of $16 \mathrm{~S}$ rRNA genes and viable count in different test groups. ${ }^{1}$

\begin{tabular}{|c|c|c|c|c|c|c|}
\hline & \multicolumn{6}{|l|}{ Animal groups ${ }^{2}$} \\
\hline & AIN-76A & CS-ctrl & $299 v$ & LF & LP & LFP \\
\hline \multicolumn{7}{|l|}{ Diversity } \\
\hline Richness (T-RFLP) & $10.5(5.25-15.3)$ & $9(8-15)$ & $23^{\star}(13-26)$ & $17(15-20)$ & $20.5^{* \star}(17.8-23.5)$ & $14(12-17)$ \\
\hline Cho 1 (NGS) & $97(89-103)$ & $83(75-91)$ & $94(87.8-94.8)$ & $105^{*}(97.1-108)$ & 101 (85.5-108) & $118^{* \star}(96-121)$ \\
\hline $\begin{array}{l}\text { Shannon diversity } \\
\text { index (T-RFLP) }\end{array}$ & $2.08(1.32-2.35)$ & $1.87(1.61-2.30)$ & $2.34(2.16-2.87)$ & $2.43^{*}(2.37-2.58)$ & $2.68^{\star \star \star}(2.54-2.75)$ & $2.34(1.92-2.41)$ \\
\hline $\begin{array}{l}\text { Shannon diversity } \\
\text { Index (NGS) }\end{array}$ & $5.23^{\star \star}(5.17-5.38)$ & $4.73(4.62-4.82)$ & $5.19^{*}(5.09-5.34)$ & $4.71(4.49-4.99)$ & $4.95(4.86-5.09)$ & $5.54^{\star \star}(4.93-5.84)$ \\
\hline $\begin{array}{l}\text { Simpson diversity } \\
\text { index (T-RFLP) }\end{array}$ & $0.826(0.667-.866)$ & $0.792(0.714-.842)$ & $0.858(0.826-923)$ & $0.884^{*}(0.863-.905)$ & $0.903^{* \star \star}(0.891-918)$ & $0.848(0.772-892)$ \\
\hline $\begin{array}{l}\text { Simpson diversity } \\
\text { index (NGS) }\end{array}$ & $0.96^{*}(0.95-0.96)$ & $0.94(0.92-0.94)$ & $0.95(0.94-0.96)$ & $0.89(0.87-0.93)$ & $0.94(0.94-0.95)$ & $0.97^{\star}(0.94-0.97)$ \\
\hline \multicolumn{7}{|l|}{ Quantification of $16 S$} \\
\hline \multicolumn{7}{|l|}{ rDNA (copies/g tissue) } \\
\hline Total bacteria & $8.68(8.41-8.79)$ & $8.95(8.76-9.04)$ & $8.70(8.56-9.01)$ & $9.15(9.00-9.36)$ & $9.05(8.94-9.21)$ & $8.92(8.80-9.05)$ \\
\hline Clostridium leptum & $7.12(6.81-7.27)$ & $7.03(6.97-7.19)$ & $6.92(6.68-7.04)$ & $9.15(9.00-9.36)$ & $9.05(8.94-9.21)$ & $8.92(8.80-9.05)$ \\
\hline \multicolumn{7}{|l|}{$\begin{array}{l}\text { Viable count (log cfu/g } \\
\text { caecum content) }\end{array}$} \\
\hline Lactobacilli & $5.72^{\star}(5.18-5.98)$ & $0(0-0)$ & $6.48^{* \star * *}(6.37-6.59)$ & $5.59^{*}(4.99-6.14)$ & $6.18^{\star \star \star}(5.90-6.57)$ & $4.93(3.55-5.64)$ \\
\hline Enterobacteriaceae & $2.95(1.97-3.64)$ & $3.62(3.29-4.09)$ & $3.73(3.37-4.17)$ & $3.26(2.80-3.54)$ & $2.63^{\star}(2.37-2.89)$ & $2.3(0-3.50)$ \\
\hline
\end{tabular}




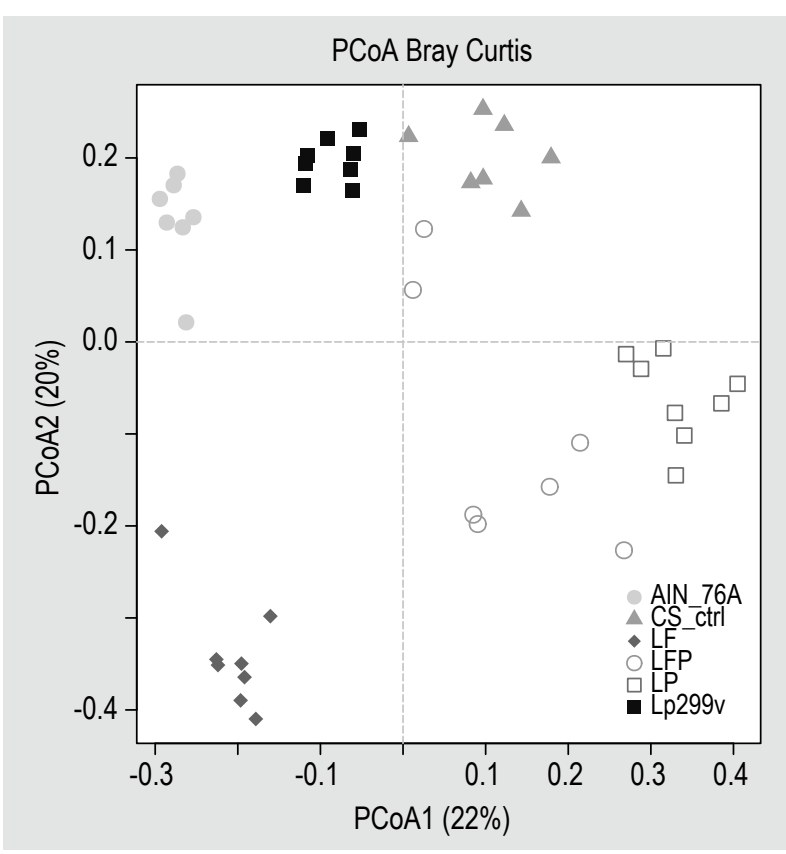

Figure 4. Principal coordinates analysis (PCOA) of beta diversity using Bray-Curtis distances shows clear separation between the tested six groups. Each point represents one mouse and the tested six groups are marked with different shapes and greyscale colours.

\section{Discussion}

The mouse model used in the present study was developed with the primary goal to build an in vivo, screening model for the evaluation of potentially probiotic strains of Lactobacillus (Linninge et al., 2015). Requirements for the model included (1) the natural microbiota of the individual animals should be as uniform as possible, (2) the spontaneously occurring Lactobacillaceae should be minimised, and (3) all animals should from the start harbour substantial amounts of Enterobacteriaceae. All these demands have been fulfilled by the model: The individual differences in microbiota within each group were considerably smaller than that between the different groups (Figure 2 and 4). No lactobacilli, but a measurable amount of Enterobacteriaceae, were detected by viable count in the CSctrl, diet control group (Table 3). Furthermore, in contrast to the conventional AIN-76A diet, the CS-ctrl diet favoured other components of the microbiota, e.g. the gram-negative families Bacteroidaceae and Porphyromonadaceae (data not shown).

A limitation of the present model-design is that animals given different bacterial supplements cannot be maintained in the same cage, i.e. a certain 'cage effect' cannot be ruled out in the present study design. However, the microbiota of individual mice living in the same cage, under more conventional circumstances can differ widely in spite of the same cage-environment. At the same time, the condition of

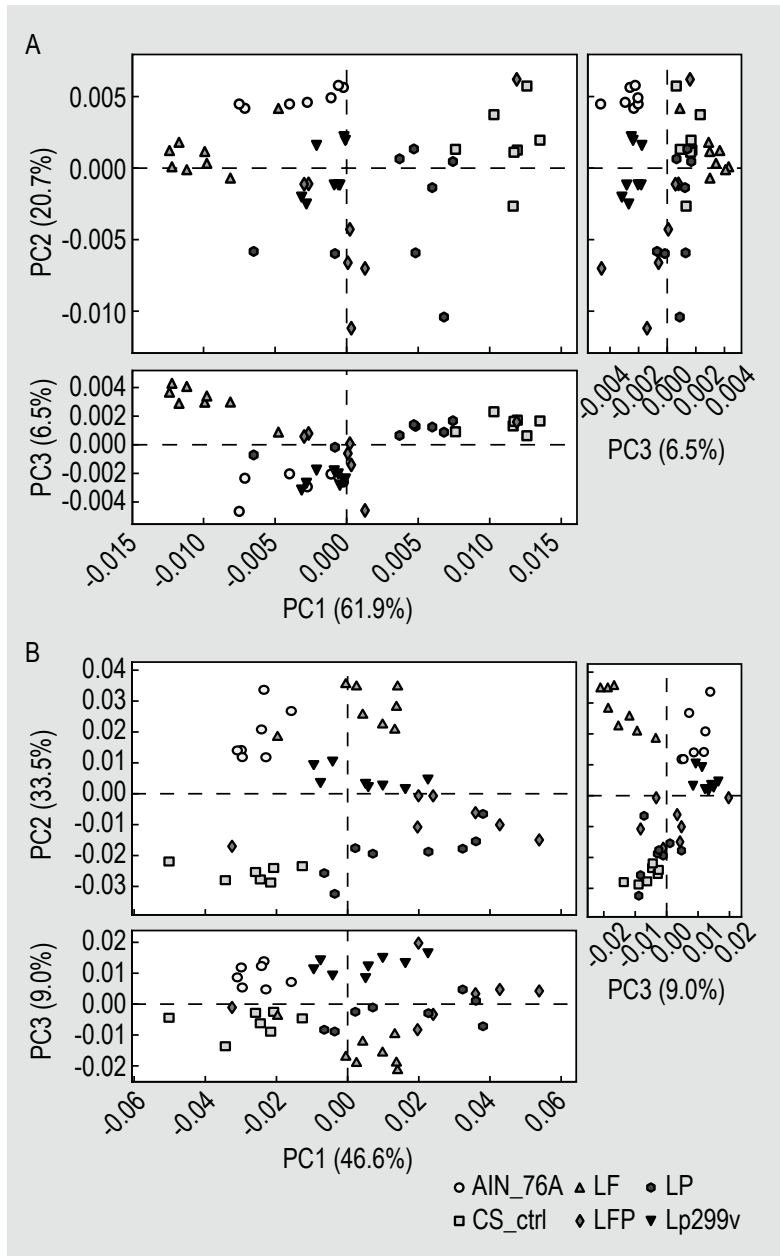

Figure 5. Principal component analysis (PCA) of the relative abundance of inferred KEGG pathways (A) and modules (B) shows considerable difference in the microbiome functions between the tested six groups. Each point represents one mouse and the groups are marked with different shapes and colours.

the present model strongly equalises the microbiota from the start, which should minimise individual differences (Linninge et al., 2015). Thus, the risk of a cage-effect is somewhat decreased by the selective power of the model. The fact that the animals in groups CS-ctrl and 299v cluster so closely together, while the other groups are so different, points in the same direction, i.e. that the eventual cageeffect seems to be of secondary importance (Figure 4).

A highly interesting feature for probiotics is the ability to induce increased diversity of the gut-microbiota. Despite the difference in resolution capacity between the T-RFLP and NGS, the diversity estimation of the caecal microbiota points in the same direction. All the Lactobacillus-supplemented groups showed, statistically significant increase in alpha diversity in either T-RFLP, NGS or both analysis (Table 3). Regarding the beta-diversity (Figure 4), it was observed that the effect from probiotic 
A

B

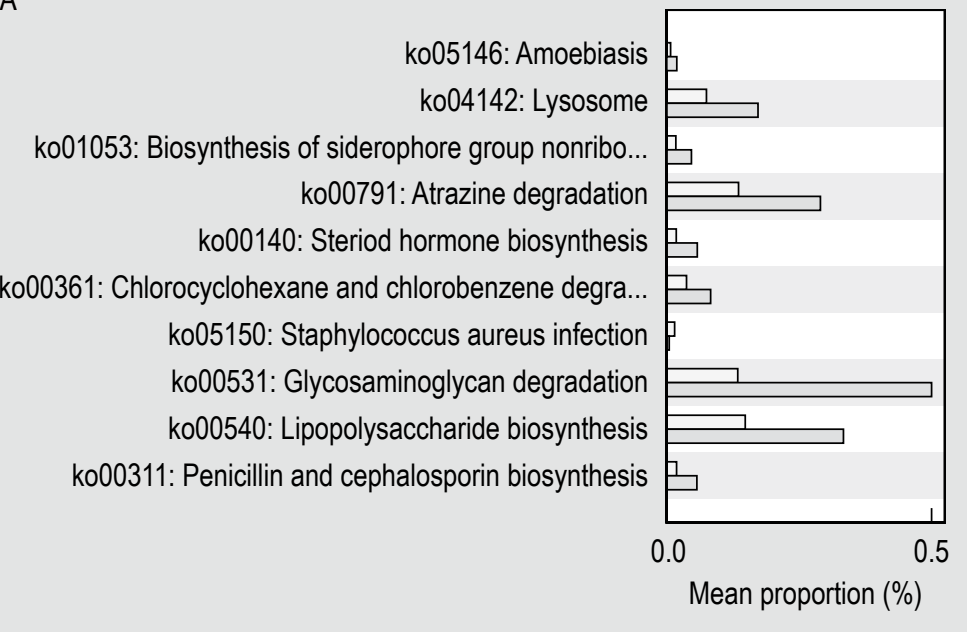

$95 \%$ confidence intervals
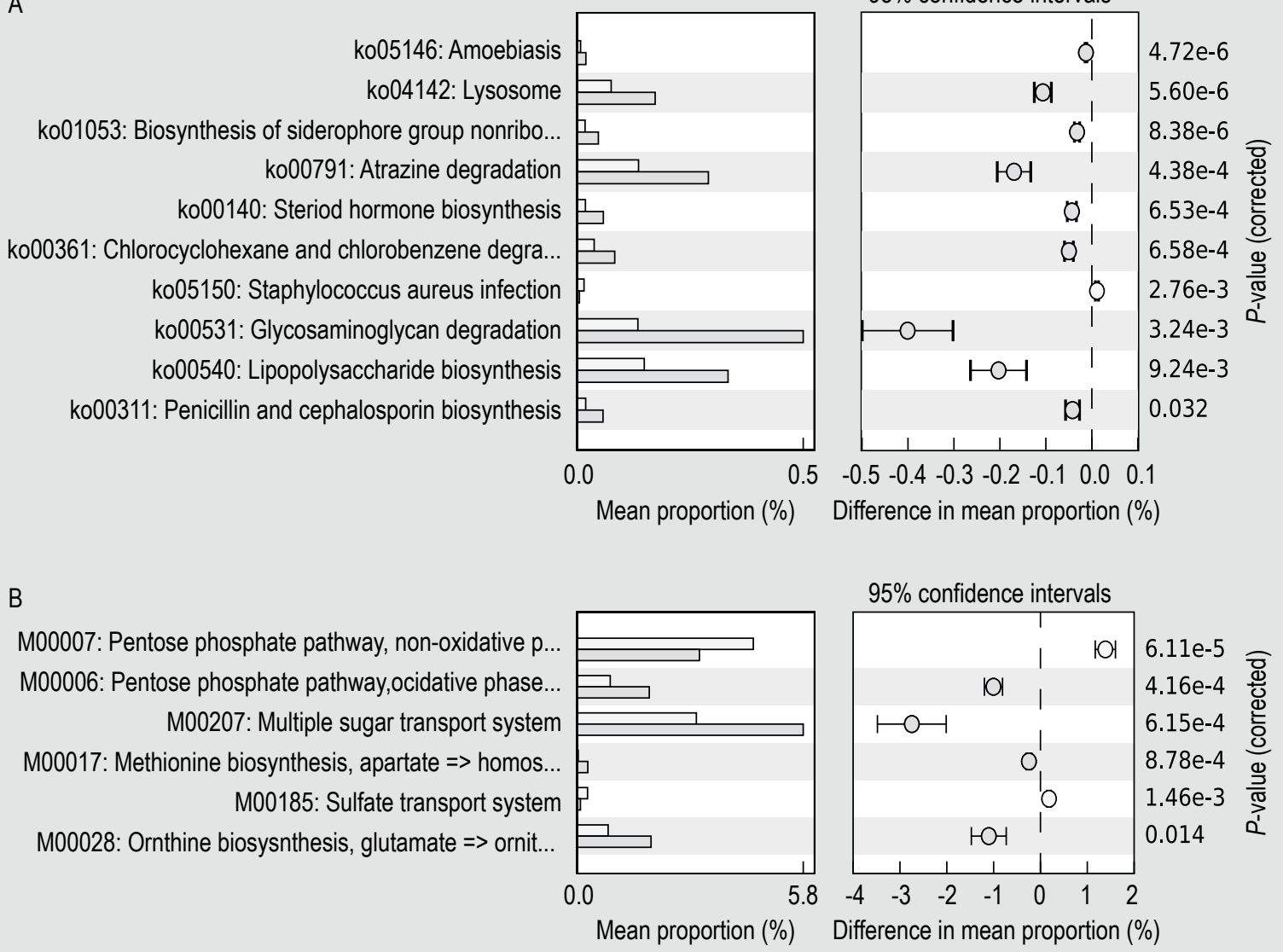

95\% confidence intervals

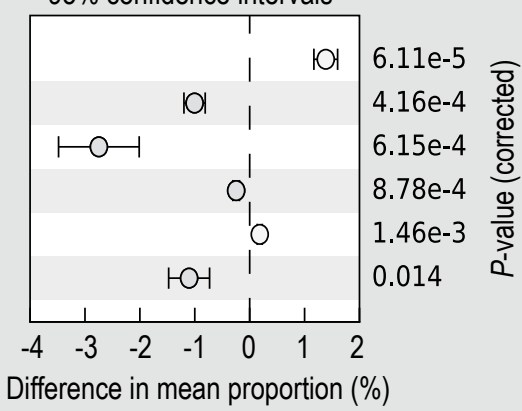

$$
\text { AIN_76A } \square \text { CS_ctrl }
$$

Figure 6. Extended error bar plot showing significantly different abundant KEGG pathways $(A)$ and modules (B) between AIN-76A and CS-ctrl. $P$-values are corrected with Bonferroni correction.

strain L. plantarum 299v differed largely from the other Lactobacillus supplemented groups and was more similar to the two control groups. This indicates that just a smaller change in the dominant bacterial taxa was induced by $L$. plantarum 299v. In contrast, the Shannon diversity index was significantly increased (Table 3 ), which indicates that the number of rare taxa had increased in the $299 \mathrm{~V}$ group. The 299v-supplement favoured bifidobacteria to highest degree (Figure 3) but showed no effect against Enterobacteriaceae (Table 3).

Generally, the three tested combinations of novel strainsupplementations influenced the microbiota in a way different from L. plantarum 299v (Figure 4), indicating strain specific effects. The observed differences in microbiota between animals in group LPF seem to be imposed by another parameter than the supplementation of the mixture of all four strains (group LFP). The heterogeneity within the LPF-group may be a result of stress as one of the animals was found injured and had to be taken away; maybe the stress was due to aggression between certain animals in this particular group. No significant changes in the viable count of lactobacilli and Enterobacteriaceae could be seen in this disturbed group (group LPF) compared to group CS-ctrl (Table 3).

The strain specific effects were not limited to the influence on the bacterial members of the microbiota, but also to the inferred microbiome functions (Figure 5). Interestingly, a change in the sort of dietary carbohydrate in CS-ctrl led to a substantial change in microbiome functions (Figure 6). Bacterial functions involved in glycosaminoglycan degradation (Ko00531) and LPS biosynthesis (Ko00540) were enriched when the diet carbohydrate source was only corn starch. On the contrary, LF suppressed these two pathways (Figure 7). Bacterial glycosaminoglycan degradation has been linked to inflammatory bowel disease in both animals and humans (Lee et al., 2009; Murch et al., 1993). LPS is well known to induce production of proinflammatory mediators. Furthermore, LF had significantly enriched pathways involved in the SCFA production. Thus L. fermentum GOS47 and L. fermentum GOS1 should be considered for further investigations as candidate probiotics. On the other hand, the viable count 
Table 4. Significantly enriched KEGG pathways and modules with large effect size ( $\eta 2>0.80)$. $P$-values were corrected with Bonferroni correction. ${ }^{1}$

\begin{tabular}{|c|c|c|c|c|c|c|c|}
\hline \multirow[t]{2}{*}{ KEGG pathwyas } & \multirow{2}{*}{$\begin{array}{l}P \text {-values } \\
\text { (corrected) }\end{array}$} & \multirow{2}{*}{$\begin{array}{l}\text { Effect } \\
\text { size }\end{array}$} & \multicolumn{5}{|c|}{ Animal groups $^{2}$} \\
\hline & & & CS-ctrl & LF & LFP & LP & Lp299v \\
\hline ko00660: C5-Branched dibasic acid metabolism & $2.55 \mathrm{E}-15$ & 092 & $2.43(0.03)$ & $2.71(0.03)$ & $2.35(0.06)$ & $2.41(0.04)$ & $2.39(0.02)$ \\
\hline ko00730: Thiamine metabolism & $1.14 \mathrm{E}-13$ & 090 & $1.7(0.02)$ & $2.11(0.06)$ & $1.9(0.06)$ & $1.82(0.05)$ & $1.94(0.03)$ \\
\hline ko00253: Tetracycline biosynthesis & $1.45 \mathrm{E}-13$ & 090 & $0.52(0.02)$ & $0.91(0.05)$ & $0.63(0.06)$ & $0.6(0.06)$ & $0.71(0.02)$ \\
\hline k000061: Fatty acid biosynthesis & $1.29 \mathrm{E}-12$ & 088 & $1.36(0.02)$ & $1.8(0.07)$ & $1.49(0.07)$ & $1.47(0.06)$ & $1.58(0.03)$ \\
\hline ko00290: Valine, leucine and isoleucine biosynthesis & $1.31 \mathrm{E}-12$ & 088 & $2.65(0.03)$ & $2.83(0.02)$ & $2.62(0.04)$ & $2.67(0.02)$ & $2.68(0.01)$ \\
\hline k000550: Peptidoglycan biosynthesis & $3.62 \mathrm{E}-12$ & 087 & $1.65(0.02)$ & $1.86(0.04)$ & $1.76(0.03)$ & $1.72(0.02)$ & $1.76(0.02)$ \\
\hline ko00640: Propanoate metabolism & $7.65 \mathrm{E}-12$ & 087 & $0.6(0.01)$ & $0.69(0.02)$ & $0.6(0.02)$ & $0.58(0.02)$ & $0.65(0.01)$ \\
\hline ko00620: Pyruvate metabolism & $5.85 \mathrm{E}-11$ & 085 & $1.2(0.01)$ & $1.27(0.01)$ & $1.21(0.02)$ & $1.21(0.01)$ & $1.26(0.01)$ \\
\hline ko00270: Cysteine and methionine metabolism & $5.26 \mathrm{E}-10$ & 083 & $1.18(0.01)$ & $1.31(0.01)$ & $1.26(0.03)$ & $1.23(0.03)$ & $1.3(0.02)$ \\
\hline $\begin{array}{l}\text { ko00400: Phenylalanine, tyrosine and tryptophan } \\
\text { biosynthesis }\end{array}$ & $7.28 \mathrm{E}-10$ & 083 & $1.11(0.02)$ & $1.27(0.02)$ & $1.17(0.06)$ & $1.11(0.02)$ & $1.24(0.01)$ \\
\hline ko00195: Photosynthesis & $1.44 \mathrm{E}-09$ & 082 & $0.45(0.02)$ & $0.52(0.01)$ & $0.47(0.02)$ & $0.44(0.02)$ & $0.49(0.01)$ \\
\hline ko00900: Terpenoid backbone biosynthesis & 2.63E-09 & 081 & $1.1(0.02)$ & $1.47(0.06)$ & $1.3(0.09)$ & $1.26(0.07)$ & $1.33(0.02)$ \\
\hline ko00785: Lipoic acid metabolism & $3.49 \mathrm{E}-09$ & 081 & $0.73(0.07)$ & $0.37(0.05)$ & $0.69(0.06)$ & $0.74(0.1)$ & $0.6(0.04)$ \\
\hline ko00471: D-Glutamine and D-glutamate metabolism & $5.81 \mathrm{E}-09$ & 080 & $1.62(0.02)$ & $1.97(0.05)$ & $1.84(0.09)$ & $1.82(0.07)$ & $1.87(0.02)$ \\
\hline ko00760: Nicotinate and nicotinamide metabolism & $6.90 \mathrm{E}-09$ & 080 & $0.83(0.01)$ & $1.03(0.02)$ & $0.92(0.05)$ & $0.89(0.04)$ & $0.9(0.02)$ \\
\hline \multicolumn{8}{|l|}{ KEGG modules } \\
\hline M00222: Phosphate transport system & $5.09 \mathrm{E}-13$ & 089 & $2.72(0.02)$ & $3.31(0.09)$ & $2.73(0.14)$ & $2.58(0.07)$ & $2.57(0.13)$ \\
\hline M00157: F-type ATPase, bacteria & $5.70 \mathrm{E}-13$ & 089 & $2.81(0.07)$ & $3.43(0.09)$ & $2.85(0.15)$ & $2.61(0.11)$ & $3.14(0.09)$ \\
\hline M00164: ATP synthase & $5.70 \mathrm{E}-13$ & 089 & $2.81(0.07)$ & $3.43(0.09)$ & $2.85(0.15)$ & $2.61(0.11)$ & $3.14(0.09)$ \\
\hline $\begin{array}{l}\text { M00001: Glycolysis (Embden-Meyerhof pathway), } \\
\text { glucose => pyruvate }\end{array}$ & $1.39 \mathrm{E}-12$ & 088 & $3.85(0.07)$ & $4.47(0.1)$ & $3.87(0.12)$ & $3.84(0.1)$ & $4.17(0.06)$ \\
\hline $\begin{array}{l}\text { M00022: Shikimate pathway, phosphoenolpyruvate + } \\
\text { erythrose-4P => chorismate }\end{array}$ & $2.65 \mathrm{E}-12$ & 088 & $2.17(0.04)$ & $3.1(0.12)$ & $2.54(0.16)$ & $2.34(0.18)$ & $2.88(0.07)$ \\
\hline $\begin{array}{l}\text { M00002: Glycolysis, core module involving } \\
\text { three-carbon compounds }\end{array}$ & $1.00 \mathrm{E}-11$ & 087 & $3.33(0.08)$ & $3.87(0.09)$ & $3.4(0.09)$ & $3.34(0.1)$ & $3.64(0.05)$ \\
\hline M00359: Aminoacyl-tRNA biosynthesis, eukaryotes & $1.18 \mathrm{E}-11$ & 087 & $2.78(0.06)$ & $3.36(0.1)$ & $2.87(0.11)$ & $2.81(0.11)$ & $3.14(0.04)$ \\
\hline M00360: Aminoacyl-tRNA biosynthesis, prokaryotes & $1.48 \mathrm{E}-11$ & 086 & $2.81(0.06)$ & $3.37(0.1)$ & $2.9(0.1)$ & $2.84(0.1)$ & $3.17(0.05)$ \\
\hline $\begin{array}{l}\text { M00007: Pentose phosphate pathway, non-oxidative } \\
\text { phase, fructose } 6 \mathrm{P}=>\text { ribose } 5 \mathrm{P}\end{array}$ & $2.39 \mathrm{E}-11$ & 086 & $3.14(0.09)$ & $4.21(0.13)$ & $3.4(0.2)$ & $3.26(0.24)$ & $3.82(0.08)$ \\
\hline M00115: NAD biosynthesis, aspartate $=>$ NAD & $1.34 \mathrm{E}-10$ & 084 & $1.51(0.1)$ & $2.84(0.14)$ & $2.06(0.27)$ & $1.87(0.26)$ & $2.03(0.1)$ \\
\hline M00178: Ribosome, bacteria & $2.80 \mathrm{E}-10$ & 084 & $2.56(0.08)$ & $3.2(0.11)$ & $2.74(0.11)$ & $2.67(0.12)$ & $2.92(0.04)$ \\
\hline $\begin{array}{l}\text { M00006: Pentose phosphate pathway, oxidative } \\
\text { phase, glucose } 6 \mathrm{P}=>\text { ribulose } 5 \mathrm{P}\end{array}$ & $4.79 \mathrm{E}-10$ & 083 & $1.86(0.08)$ & $0.6(0.12)$ & $1.07(0.26)$ & $1.41(0.28)$ & $1.04(0.09)$ \\
\hline M00026: Histidine biosynthesis, PRPP => histidine & $7.18 \mathrm{E}-10$ & 083 & $2.66(0.06)$ & $3.33(0.1)$ & $2.73(0.17)$ & $2.71(0.13)$ & $2.61(0.13)$ \\
\hline $\begin{array}{l}\text { M00004: Pentose phosphate pathway } \\
\text { (Pentose phosphate cycle) }\end{array}$ & $1.19 \mathrm{E}-09$ & 082 & $2.33(0.07)$ & $1.05(0.18)$ & $1.6(0.26)$ & $1.94(0.27)$ & $1.63(0.12)$ \\
\hline M00207: Multiple sugar transport system & 2.74E-09 & 081 & $5.81(0.57)$ & $1.75(0.46)$ & $2.86(0.92)$ & $3.95(0.89)$ & $2.42(0.31)$ \\
\hline $\begin{array}{l}\text { M00003: Gluconeogenesis, oxaloacetate => } \\
\text { fructose- } 6 \mathrm{P}\end{array}$ & $4.02 \mathrm{E}-09$ & 081 & $3.22(0.09)$ & $3.68(0.1)$ & $3.03(0.21)$ & $3.01(0.1)$ & $3.39(0.08)$ \\
\hline
\end{tabular}

${ }^{1}$ Data presented as mean ( \pm standard deviation) of relative abundance.

${ }^{2}$ Animal diet groups are explained in Table 1.

of Enterobacteriaceae was significantly decreased only in group LP, which can be a highly beneficial trait for a potential probiotic strain. The question remains whether the observed effect requires the presence of both strains, 


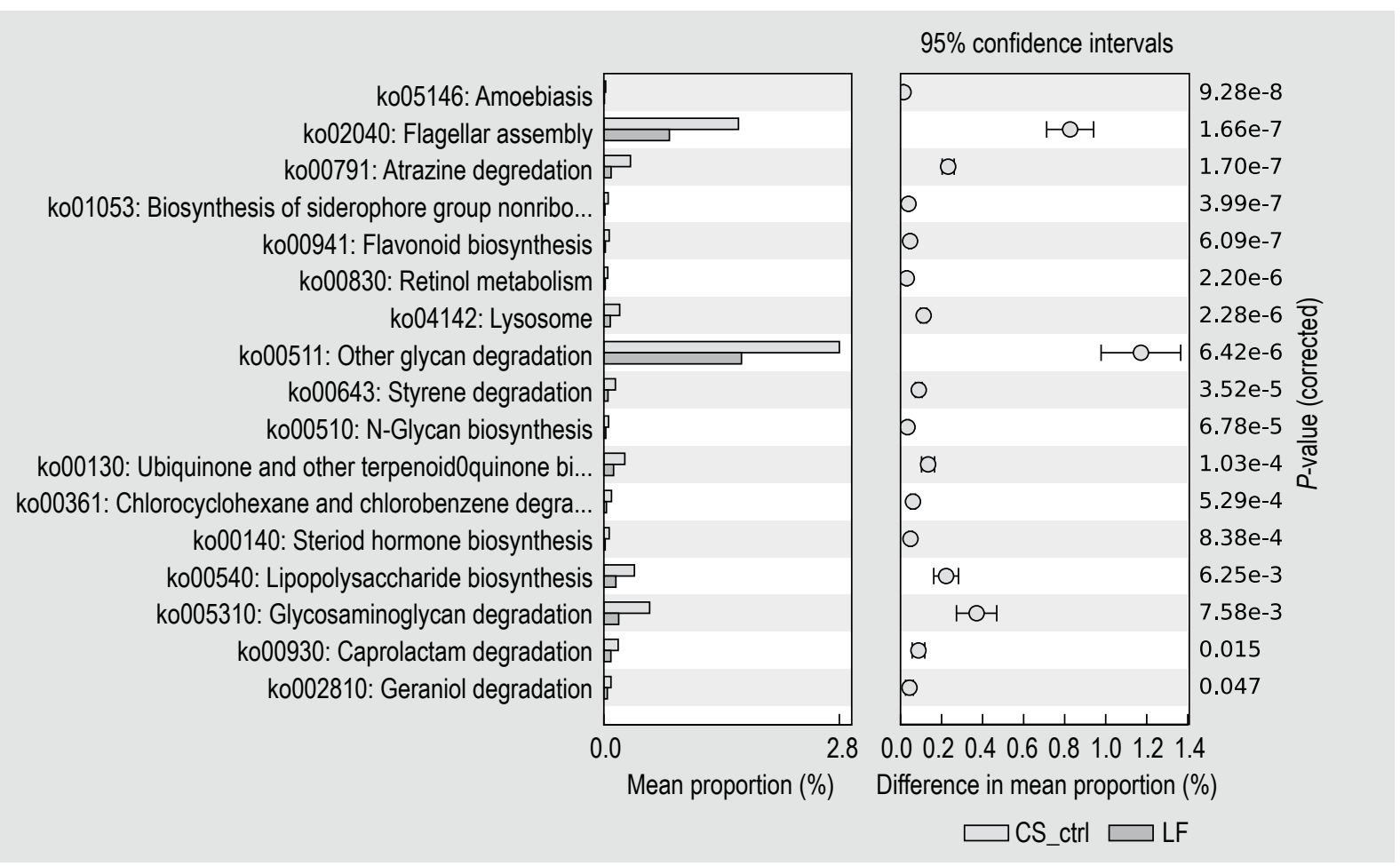

Figure 7. Extended error bar plot showing significantly different abundant KEGG pathways between CS-ctrl and LF. $P$-values are corrected with Bonferroni correction.

or if one of them is sufficient? This is a question that can be solved by applying the present screening model on animals given singular strains and then compare them with animals given the two strains together. However, this is outside the scope of the present study, but would be an important follow up study.

Several probiotic strains of the species $L$. fermentum and $L$. plantarum are commercially available. Two such examples are L. plantarum $299 \mathrm{v}$ and $L$. fermentum ME-3, respectively. The literature about the former are vast, and the strain $299 \mathrm{v}$ has, for example, been proved efficient to mitigate irritable bowel syndrome (Ducrotté et al., 2012; Nobaek et al., 2000). Strain 299v was also able to increase the diversity of the abundant microbiota on colonic mucosa in humans, after a four weeks intervention period (Karlsson et al., 2010). L. fermentum ME-3 has been shown to possess antimicrobial activity against intestinal pathogens and to have an outstanding high antioxidative activity (Mikelsaar and Zilmer, 2009). Generally speaking, the species $L$. plantarum and $L$. fermentum often occupy similar ecological niches in nature, they can both frequently be isolated from lactic acid fermented foods, but also from the gastro-intestinal tract of humans and animals. But, the two species are quite different, both when it comes to phenotype and genotype, so they can be expected to have different physiological and immunological effects in the gastro-intestinal tract. And perhaps, there could be advantages in combining strains of the two species in a probiotic mixture. Nevertheless, the
LP-supplementation affected not only the viable count of lactobacilli (seen as an increase), and of Enterobacteriaceae (seen as a decrease), but resulted in a substantial increase in the proportion of lactobacilli in comparison with the total microbiota (Figure 3). No such effect was seen in the other Lactobacillus-supplemented groups.

\section{Conclusions}

The experimental animal model with equalised microbiota was proved suitable for in vivo studies on the effect of bacterial supplements on the microbiota. Supplementation with $L$. fermentum GOS47 and L. fermentum GOS1 and the mixture of $L$. fermentum GOS57 + L. plantarum GOS42 strongly affected the gut microbiota and increased diversity. Furthermore, the former combination may induce anti-inflammatory activity and SCFA production in the microbiota (inferred from 16S rRNA-gene compositional data), and the latter combination decreased the numbers of Enterobacteriaceae, and improved the abundance of lactobacilli. These two mixtures seem to have probiotic potential that call for further investigations.

\section{Acknowledgements}

Marie Kala and Milica Mirković are greatly thanked for technical assistance. Doctor P. Håkansson Foundation (Eslöv, Sweden) has financially supported the study which is highly appreciated. 


\section{Conflicts of interest}

Göran Molin and Siv Ahrné are minor, minority stockholders in the public company, Probi AB. Caroline Linninge has taken up a position in the public company BioGaia $\mathrm{AB}$, after the experimental part of the project was finalised, and the manuscript draft had been prepared.

\section{References}

Abrahamsson, T.R., Jakobsson, H.E., Andersson, A.F., Björkstén, B., Engstrand, L. and Jenmalm, M.C., 2012. Low intestinal microbial diversity during the first month of life was associated with subsequent atopic eczema. Journal of Allergy and Clinical Immunology 129: 434-440.

Abubucker, S., Segata, N., Goll, J., Schubert, A.M., Izard, J., Cantarel, B.L., Rodriguez-Mueller, B., Zucker, J., Thiagarajan, M., Henrissat, B., White, O., Kelley, S.T., Methé, B., Schloss, P.D., Gevers, D., Mitreva, M. and Huttenhower, C., 2012. Metabolic reconstruction for metagenomic data and its application to the human microbiome. PLoS Computational Biology 8: e1002358.

Callahan, B.J., McMurdie, P.J., Rosen, M.J., Han, A.W., Johnson, A.J.A. and Holmes, S.P., 2016. Nature Methods 13: 581-583.

Caporaso, J.G., Kuczynski, J., Stombaugh, J., Bittinger, K., Bushman, F.D., Costello, E.K., Fierer, N., Peña, A.G., Goodrich, J.K., Gordon, J.I., Huttley, G.A., Kelley, S.T., Knights, D., Koenig, J.E., Ley, R.E., Lozupone, C.A., McDonald, D., Muegge, B.D., Pirrung, M., Reeder, J., Sevinsky, J.R., Turnbaugh, P.J., Walters, W.A., Widmann, J., Yatsunenko, T., Zaneveld, J. and Knight, R., 2010. QIIME allows analysis of high-throughput community sequencing data. Nature Methods 7: 335-336

Constante, M., Fragoso, G., Calvé, A., Samba-Mondonga, M. and Santos, M.M., 2017. Dietary heme induces gut dysbiosis, aggravates colitis, and potentiates the development of adenomas in mice. Frontiers in Microbiology 8: article 1809.

DeSantis, T.Z., Hugenholtz, P., Larsen, N., Rojas, M., Brodie, E.L., Keller, K., Huber, T., Dalevi, D., Hu, P. and Andersen, G.L., 2006. Greengenes, a chimera-checked 16S rRNA gene database and workbench compatible with ARB. Applied and Environmental Microbiology 72: 5069-5072.

Ducrotté, P., Sawant, P. and Jayanthi, V., 2012. Clinical trial: Lactobacillus plantarum 299v (DSM 9843) improves symptoms of irritable bowel syndrome. World Journal of Gastroenterology 18: 4012-4018.

Fuller, R., 1989. Probiotics in man and animals. Journal of Applied Bacteriology 66: 365-368.

Håkansson, Å., Tormo-Badia, N., Baridi, A., Xu, J., Molin, G., Hagslätt, M.-L., Karlsson, C., Jeppsson, B., Cilio, C.M. and Ahrne, S., 2015. Immunological alteration and changes of gut microbiota after dextran sulfate sodium (DSS) administration in mice. Clinical and Experimental Medicine 15: 107-120. https://doi.org/10.1007/ s10238-013-0270-5

Hooton, T.M. and Stamm, W.E., 1997. Diagnosis and treatment of uncomplicated urinary tract infection. Infectious Disease Clinics of North America 11: 551-581.
Ismail, I.H., Oppedisano, F., Joseph, S.J., Boyle, R.J., Licciardi, P.V., Robins-Browne, R.M. and Tang, M.L.K., 2012. A more diverse intestinal microbiota in the first week of life is associated with a reduced risk of subsequent eczema in infants at increased risk of allergic disease. Pediatric Allergy and Immunology 23: 674-681.

Karlsson, C., Ahrné, S., Molin, G., Berggren, A., Palmquist, I., Fredrikson, G.N. and Jeppsson, B., 2010. Probiotic therapy to men with incipient arteriosclerosis initiates increased bacterial diversity in colon: a randomized controlled trial. Atherosclerosis 208: 228-233.

Karlsson, C.L., Molin, G., Cilio, C.M. and Ahrné, S., 2011a. The pioneer gut microbiota in human neonates vaginally born at term - a pilot study. Pediatric Research 70: 282-286.

Karlsson, C.L., Molin, G., Fåk, F., Johansson Hagslätt, M.L., Jakesevic, M., Håkansson, Å., Jeppsson, B., Weström, B. and Ahrné, S., 2011b. Effects on weight gain and gut microbiota in rats given bacterial supplements and a high-energy-dense diet from fetal life through to 6 months of age. British Journal of Nutrition 106: 887-895.

Langille, M.G., Zaneveld, J., Caporaso, J.G., McDonald, D., Knights, D., Reyes, J.A., Clemente, J.C., Burkepile, D.E., Thurber, R.L.V., Knight, R., Beiko, R.G. and Huttenhower, C., 2013. Predictive functional profiling of microbial communities using 16S rRNA marker gene sequences. Nature Biotechnology 31: 814-821.

Lee, B., Lee, J.H., Lee, H.S., Bae, E.A., Huh, C.S., Ahn, Y.T. and Kim, D.H., 2009. Glycosaminoglycan degradation-inhibitory lactic acid bacteria ameliorate 2,4,6-trinitrobenzenesulfonic acid-induced colitis in mice. Journal of Microbiology and Biotechnology 19: 616-621.

Linninge, C., Ahrne, S. and Molin, G., 2015. Pre-treatment with antibiotics and Escherichia coli to equalize the gut microbiota in conventional mice. Antonie van Leeuwenhoek Journal of Microbiology 107: 149-156.

Linninge, C., Roth, B., Erlanson-Albertsson, C., Molin, G., Toth, E. and Ohlsson, B., 2018. Abundance of Enterobacteriaceae in the colon mucosa in diverticular disease. World Journal of Gastrointestinal Pathophysiology 9: 18-27.

Mikelsaar, M. and Zilmer, M., 2009. L. fermentum strain ME-3 has double functional properties: antimicrobial activity against intestinal pathogens and high total antioxidative activity. Microbial Ecology in Health and Disease 21: 1-27.

Molin, G., 2008. Lactobacillus plantarum: the role in foods and in human health. In: Farnworth, E.R. (ed.) Handbook of fermented functional foods, $2^{\text {nd }}$ edition. CRC Press, Boca Raton, FL, USA, pp. 353-393.

Molin, G., Jeppsson, B., Johansson, M.L., Ahrné, S., Nobaek, S., Ståhl, M. and Bengmark, S., 1993. Numerical taxonomy of Lactobacillus spp. associated with healthy and diseased mucosa of the human intestines. Journal of Applied Bacteriology 74: 314-323.

Murch, S.H., MacDonald, T.T., Walker-Smith, J.A., Levin, M., Lionetti, P. and Klein, N.J., 1993. Disruption of sulphated glycosaminoglycans in intestinal inflammation. Lancet 341: 711-714.

Nobaek, S., Johansson, M.-L., Molin, G., Ahrné, S. and Jeppsson, B., 2000. Alteration of intestinal microflora is associated with reduction in abdominal bloating and pain in patients with irritable bowel syndrome. American Journal of Gastroenterology 95: 1231-1238.

Parker, R.B., 1974. Probiotics, the other half of the antibiotic story. Animal Nutrition Health 29: 4-8. 


\section{Linninge et al.}

Parks, D.H., Tyson, G.W., Hugenholtz, P. and Beiko, R.G., 2014. STAMP: statistical analysis of taxonomic and functional profiles. Bioinformatics 30: 3123-3124.

Penders, J., Thijs, C., Van den Brandt, P.A., Kummeling, I., Snijders, B., Stelma, F., Adams, H., Van Ree, R. and Stobberingh, E.E., 2007. Gut microbiota composition and development of atopic manifestations in infancy: the KOALA Birth Cohort Study. Gut 56: 661-667.

Poxton, I.R. and Edmond, D.M., 1995. Biological activity of Bacteroides lipopolysaccharide - reappraisal. Clinical Infectious Diseases 20: S149-S153.

Sand, E., Linninge, C., Lozinska, L., Sand, E., Linninge, C., Lozinska, L., Egecioglu, E., Roth, B., Molin, G., Weström, B., Ekblad, E. and Ohlsson, B., 2015. Buserelin treatment to rats causes enteric neurodegeneration with moderate effects on CRF-immunoreactive neurons and Enterobacteriaceae in colon, and in acetylcholinemediated permeability in ileum. BMC Research Notes 8: 824. DOI: https://doi.org/10.1186/s13104-015-1800-x

Silva, B.C., Sandes, S.H.C., Alvim, L.B., Bomfim, M.R.Q., Nicoli, J.R., Neumann, E. and Nunes, A.C., 2016. Selection of a candidate probiotic strain of Pediococcus pentosaceus from the faecal microbiota of horses by in vitro testing and health claims in a mouse model of Salmonella infection. Journal of Applied Microbiology 122: $225-238$
Svanborg, C. and Godaly, G., 1997. Bacterial virulence in urinary tract infection. Infectious Disease Clinics of North America 11: 513-529. Tulstrup, M.V.L., Christensen, E.G. Carvalho, V., Linninge, C., Ahrné, S., Højberg, O., Rask Licht, T. and Bahl, M.I., 2015. Antibiotic treatment affects intestinal permeability and gut microbial composition in Wistar rats dependent on antibiotic class. PLoS ONE 10(12): e0144854. https://doi.org/10.1371/journal.pone.0144854

Wang, M., Karlsson, C., Olsson, C., Adlerberth, I., Wold, A., Strachan, D.P., Martricardi, P.M., Åberg, N., Perkin, M.R., Tripodi, S., Coates, A.R., Hesselmar, B., Saalman, R., Molin, G. and Ahrné, S., 2008. Reduced diversity in the early fecal microbiota of infants developing atopic eczema: low diversity in early microbiota of infants developing atopy. Journal of Allergy and Clinical Immunology 121: 129-134.

Yamamoto, S., Tsukamoto, T., Terai, A., Kurazono, H., Takeda, Y. and Yoshida, O., 1997. Genetic evidence supporting the fecal-pernealurethral hypothesis in cystis caused by Eschesrichia coli. Journal of Urology 157: 1127-1129.

Zakrzewski, M., Proietti, C., Ellis, J.J., Hasan, S., Brion, M.-J., Berger, B. and Krause, L., 2017. Calypso: a user-friendly web-server for mining and visualizing microbiome-environment interactions. Bioinformatics 33: 782-783. https://doi.org/10.1093/bioinformatics/ btw725 